\title{
Effect of oxygen availability in determining clutch size in Acanthina monodon
}

\author{
Marco A. Lardies, Miriam Fernández*
}

Estación Costera de Investigaciones Marinas de Las Cruces, and Center for Advanced Studies in Ecology and Biodiversity, Departamento de Ecología, Facultad de Ciencias Biológicas, Pontificia Universidad Católica de Chile, Casilla 114-D, Santiago, Chile

\begin{abstract}
Most taxa of aquatic invertebrates exhibit (1) strong variation in number and size of offspring, and (2) an association between adult size and mode of development, and also between mode of development and size of the clutch. These patterns suggest that a similar set of constraints affects both critical life-history traits and physiology of most taxa. Evidence suggests that oxygen is limiting during early development in aggregated egg masses of marine invertebrates. We studied whether oxygen availability during early development could be a determinant of clutch size in the gastropod Acanthina monodon. We estimated intra- and extracapsular oxygen availability throughout embryo development using optic fibers and incubated capsules at different oxygen partial pressures (hypoxia, normoxia and hyperoxia) throughout development. We also compared the ratio between nurse eggs and embryos in capsules collected in situ as well as in experimental capsules. We found that intracapsular oxygen availability decreased as embryos developed $(80 \%$ air saturation in early stages to $40 \%$ air saturation in late stages). The mean number of embryos increased as oxygen availability increased from hypoxia to hyperoxia, while the total number of eggs remained constant. The mean number of embryos that developed under normoxia was similar to that recorded in fieldcollected capsules. We suggest that oxygen availability determines clutch size in this species, probably as a result of oxygen competition among siblings. This may also occur in other taxa of marine invertebrates, since oxygen is limiting in egg masses in general.
\end{abstract}

KEY WORDS: Clutch size · Gastropods · Intracapsular development · Life history · Oxygen competition · Acanthina monodon

\section{INTRODUCTION}

The life-history theory predicts that variation in number and size of offspring is determined by developmental, physiological and behavioral patterns fixed within lineages (Roff 1992, Stearns 1992). Both marine and terrestrial animals show a tremendous variation in number and size of offspring (Roff 1992, Stearns 1992). Among marine invertebrates this variation is related to modes of development; broadcasting species tend to show high fecundity and small egg size, while brooding species produce smaller clutches of larger eggs (e.g. Perron 1981, 1986, Kohn \& Perron 1994). Most

*Corresponding author. E-mail: mfernand@genes.bio.puc.cl taxa of marine invertebrates span the range between both extreme developmental modes, and also exhibit an association between small adult size and brooding (Strathmann \& Strathmann 1982). These patterns suggest that a similar set of constraints affects both critical life-history traits and the physiology of most marine invertebrate taxa. To date, our understanding of the critical factors that shape life-history traits of marine invertebrates is poor, compared to that of marine vertebrates and terrestrial animal taxa (e.g. CluttonBrock 1991, Roff 1992, Stearns 1992).

The life-history theory is strongly influenced by work on marine vertebrates and terrestrial animal taxa (vertebrates and invertebrates) especially in relation to the evolution of major traits such as the number and size of offspring. However, the constraints imposed on

(C) Inter-Research $2002 \cdot$ www.int-res.com 
aquatic and terrestrial clutches and on brooding are expected to differ. One constraint that may have important effects in aquatic systems is the capacity to provide oxygen to the brood (Strathmann \& Strathmann 1982, Chaffee \& Strathmann 1984, Strathmann \& Chaffee 1984). Oxygen has a lower diffusion coefficient and lower solubility in water than in air, and is usually a limiting factor in embryo masses of aquatic animals (Booth 1995, Strathmann \& Strathmann 1995, Cohen \& Strathmann 1996, Lee \& Strathmann 1998, Fernández et al. 2000). Oxygen limitation due to constraints in oxygen diffusion in packed embryos of marine invertebrates has been suggested by several authors (e.g. Crisp 1959, Perron \& Corpuz 1982, Chaffee \& Strathmann 1984, Pechenik 1986, Strathmann \& Strathmann 1995). Constraints on gas exchange have been implied in prosobranch capsules (Perron \& Corpuz 1982) and have recently been shown in the muricid Chorus giganteus (Cancino et al. 2000). Oxygen limitation has also been demonstrated in gelatinous egg masses of gastropods and polychaetes (Booth 1995, Strathmann \& Strathmann 1995, Cohen \& Strathmann 1996), as well as in embryo aggregations of crustaceans (Fernández et al. 2000, Baeza \& Fernández 2002). Several ecological and evolutionary consequences may be linked to this simple biophysical constraint on brood care (e.g. abundance, dispersal, speciation and extinction rates, e.g. Strathmann \& Chaffee 1984 and Valentine \& Jablonsky 1983).

The effect of oxygen on the evolution of clutch size or parental investment per offspring of marine invertebrates has not yet been addressed (e.g. Lack 1968, Clutton-Brock 1991, Roff 1992, Stearns 1992), inspite of the fact that parental investment is strongly related to the need to provide oxygen to the brood (see Lee \& Strathmann 1998, Fernández et al. 2000, Baeza \& Fernández 2002) and that some species are ideal subjects for studying the effect of oxygen availability on clutch size. For instance, prosobranch snails have multiple embryos which develop, physically enclosed, within the same structure (capsules), where oxygen partial pressure tends to be lower than ambient oxygen (Cancino et al. 2000). Females of several species of prosobranchs seem to deposit a fixed ratio of embryos and nurse eggs in benthic capsules (Spight 1976, West 1981, Gallardo \& Garrido 1987), but the mechanisms involved in nurse-egg determination and formation are not clear. We analyzed the possibility that nurse eggs of Acanthina monodon are the product of oxygen limitation during early development by comparing the ratio between the number of embryos and nurse eggs in capsules incubated at different oxygen partial pressures and in situ. In A. monodon, nurse egg-determination occurs in the zygote stage and over $90 \%$ of the eggs deposited in each capsule stop development at the zygote stage, becoming nurse eggs (Gallardo \& Garrido 1987). In order to assess whether nurse eggs are determined by oxygen availability, we (1) analyzed the relationship between capsule size and number of nurse eggs (and embryos), (2) estimated intra- and extracapsular oxygen availability throughout embryo development, and in capsules incubated at different oxygen partial pressures throughout development (hypoxia, normoxia and hyperoxia), and (3) estimated the ratio between nurse eggs and embryos in capsules collected from the field and in experimental capsules incubated under hypoxia, normoxia and hyperoxia. (We use 'oxygen availability' and 'oxygen concentration' as synonymous terms throughout the paper.) The implications of oxygen limitation in egg aggregations in determining clutch size in marine invertebrates are discussed.

\section{MATERIALS AND METHODS}

Experimental organism. Acanthina monodon inhabits rocky substrates in the low intertidal zone between 20 and $40^{\circ} \mathrm{S}$ in the southeastern Pacific (Chile). In central Chile, females larger than $30 \mathrm{~mm}$ are sexually mature and lay benthic capsules between February and July (Soto 2001). The capsules are laid close together in clusters attached to rocky platforms and boulders in areas of high wave exposure (Gallardo 1979). The capsules are flat ellipses containing both eggs and a mucus-like fluid (Gallardo 1979). The capsule wall is fairly transparent and yellowish, turning grey as the larvae develop (Gallardo 1979). Intracapsular development of A. monodon embryos is direct and embryos depend on nurse eggs to develop (Gallardo 1979). Egg development lasts between 70 and $80 \mathrm{~d}$ at about $10^{\circ} \mathrm{C}$ and between 55 and $65 \mathrm{~d}$ at temperatures ranging between 11 and $14^{\circ} \mathrm{C}$ (Gallardo 1979). In southern Chile, between 6.6 and $7.9 \%$ of the embryos develop, and in this species embryos with arrested development become nurse eggs, which are later consumed by the embryos. The number of eggs and embryos per capsule is correlated with capsule length (Gallardo 1979).

In May 2000, capsules containing eggs at different developmental stages were collected from the intertidal zone of Las Cruces, central Chile $\left(33^{\circ} 29^{\prime} \mathrm{S}\right.$, $\left.71^{\circ} 38^{\prime} \mathrm{W}\right)$. Capsule coloration was used as a preliminary, external indicator of incubation time (developmental stage), and the actual developmental stage of the embryos was assessed in the laboratory under the microscope. We collected and analyzed 239 capsules; these capsules were used to estimate the number of eggs and embryos in the field, and also embryo size. In addition, newly deposited capsules $(\mathrm{n}=54)$ were col- 
lected with the aim of incubating them in the laboratory (see next subsection). Laboratory and experimental work was conducted at the Estación Costera de Investigaciones Marinas, Las Cruces, Chile. We conducted the following sampling and laboratory experiments:

Analysis of capsules. Capsules containing embryos at different stages of development were collected to estimate the relationship between capsule length $(\mathrm{mm})$ and (1) number of eggs, and (2) number of embryos. These analyses allowed us to compare the number of embryos that develop per unit capsule size between experimental capsules and those in situ.

The total length of each capsule was measured, and the embryos and eggs were counted. The capsules analyzed ranged in length between 8.0 and $11.7 \mathrm{~mm}$. The total number of eggs and nurse egg/embryos could be estimated only during early development; 37 and 36 capsules were used in each case, respectively. For all the other developmental stages, 93 capsules were analyzed and the number of developing embryos were counted. Embryonic development was determined following the methodology of Gallardo (1979). Five stages were identified: egg, embryo with nurse eggs (early trochophore), trochophore, veliger, and juvenile. Linear regression models were fitted to the data.

The sizes of the different developmental stages were estimated (15 eggs or embryos per capsule) using a NIKON binocular. Mean size (the largest axis was used for the eggs) of the 15 embryos from each capsule ( $\mathrm{n}=$ 73) was used as a single datum. We used a 1-way ANOVA (Model I) to determine differences in mean size among embryo stages.

Oxygen availability in capsules. Laboratory experiments were conducted to determine (1) oxygen availability inside and outside the capsules of Acanthina monodon, and (2) patterns of intracapsular oxygen availability throughout embryo development.

Capsules from different females were collected in the study area, transported to the laboratory, and maintained at constant temperature $\left(18^{\circ} \mathrm{C}\right)$ and salinity (32 ppm), in well-aerated seawater (using air pumps), for at least $1 \mathrm{~d}$ before oxygen measurements were conducted. The experimental temperature used has been frequently observed throughout the distributional range of the species during the reproductive season. Capsule size ranged between 9.3 and $11.6 \mathrm{~mm}$ length. Oxygen availability was determined using an optic fiber (Microx I, PRESENS) with a tip diameter of between 20 and $50 \mu \mathrm{m}$. The optic fiber was calibrated in a solution saturated with $\mathrm{Na}_{2} \mathrm{O}_{3} \mathrm{~S}$ $(0 \%$ air saturation) and in aerated water $(100 \%$ air saturation). The calibration and experiments were conducted at a constant temperature $\left(18^{\circ} \mathrm{C}\right)$ using a water bath. After calibration, oxygen availability (\% air saturation) was measured outside and then inside the capsules for $15 \mathrm{~min}$. The optic fiber was inserted in the center of the capsule and the capsule was immersed in water saturated with oxygen during the measurements. Due to the agitation produced by the air pumped into the experimental container, the embryos inside the capsule were homogeneously distributed in the capsule (during early development embryos seem to be more aggregated in the mucuslike fluid than in later stages). During the $15 \mathrm{~min}$ measurements, oxygen availability was recorded every $5 \mathrm{~s}$. We ran the measurements for $15 \mathrm{~min}$ to obtain several estimates and avoid measurement errors. The first and the last $2.5 \mathrm{~min}$ were discarded to allow for possible disturbances when the fiber was inserted or removed. Thus, oxygen availability estimations are the average of the remaining $10 \mathrm{~min}$ of measurements. At least 4 replicates per developmental stage were conducted. A 1-way ANOVA (Model I) was used to compare mean oxygen availability inside the capsule throughout embryo development among different developmental stages. Five levels (stages) were used in the embryo development treatment. No transformations of the data were necessary since the assumptions of the ANOVA model were met. A posteriori Tukey's test (HSD) was conducted to determine differences among levels (Sokal \& Rohlf 1995).

Development of embryos in capsules under different, experimental oxygen partial pressures. Laboratory experiments were conducted to determine if the number of nurse eggs per embryo and per unit capsule size was fixed or was the result of the environmental conditions to which eggs are exposed during early development. Newly deposited capsules (randomly selected) were incubated at different oxygen partial pressures until embryo development was completed. Oxygen treatments were (1) hypoxia (70\% air saturation: $10 \% \mathrm{O}_{2}, 0.3 \% \mathrm{CO}_{2}$ and $89.7 \%$ $\left.\mathrm{N}_{2}\right)$, (2) normoxia $\left(100 \%\right.$ air saturation: $21 \% \mathrm{O}_{2}$ $0.3 \% \mathrm{CO}_{2}$ and $\left.78.7 \% \mathrm{~N}_{2}\right)$, and (3) hyperoxia $(165 \%$ air saturation: $31 \% \mathrm{O}_{2}, 0.3 \% \mathrm{CO}_{2}$ and $68.7 \% \mathrm{~N}_{2}$ ). Capsules $(n=54)$ were randomly assigned to the 3 experimental treatments; 18 capsules were used per treatment but, since the capsules were incubated in groups of 6 in $300 \mathrm{ml}$ containers, they were considered pseudoreplicates. Thus, a single datum was obtained by averaging all the capsules analyzed from each container for both variables (oxygen availability and developing embryos) and only 3 replicates were considered for each treatment. The size of the capsules used in the experiment ranged between 10 and $11.5 \mathrm{~mm}$, and there were not significant differences in mean capsule size among treatments (1-way 


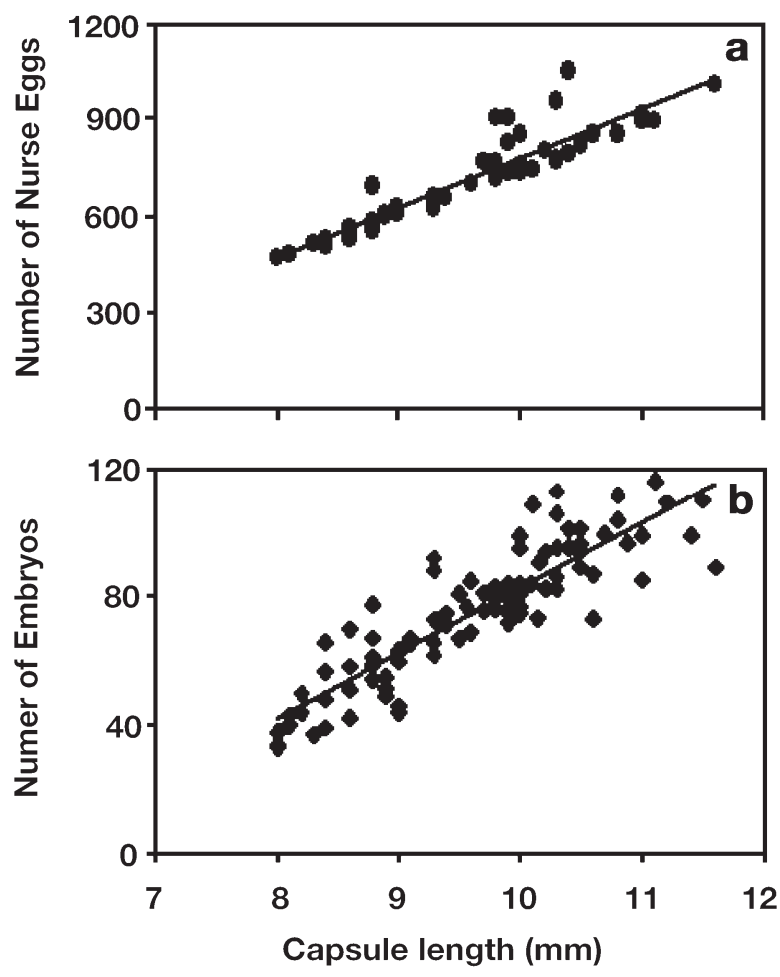

Fig. 1. Acanthina monodon. (a) Relationship between capsule length and total number of nurse eggs in the capsule, and (b) number of embryos that develop. Lines indicate predicted relationship after adjusting a linear regression

ANOVA, $\left.F_{2,51}=5.62, \mathrm{p}=0.152\right)$. The containers were placed in a water bath maintained at $18^{\circ} \mathrm{C}$. Extraand intracapsular oxygen availability was measured at the beginning ( $9 \mathrm{~d}$ after the start of incubation) and at the end (35 d of development) of the experimental period, using an optic fiber, and following the same protocol described above. Three of the 6 capsules from each container were used in each occasion, and under no circumstances were capsules re-used, ensuring independence of the oxygen measurements. Mean intra- and extracapsular oxygen availability was estimated for each container (average of oxygen availability of the 3 capsules). As described in the preceding subsection, oxygen measurements were conducted for $15 \mathrm{~min}$, but mean oxygen availability was estimated using only the measurements of the middle $10 \mathrm{~min}$.

Experimental treatments were effective throughout development (measurements were also made 9 and $35 \mathrm{~d}$ after development started); the oxygen partial pressure in the incubation tanks (extracapsular oxygen partial pressure) was significantly different among treatments (2-way ANOVA, $F_{2,12}=156.3$, p $<0.0001$; see Fig. 2b) and between early and late development
(ANOVA, $\left.F_{1,12}=7.9, \mathrm{p}=0.015\right)$. The interaction was not significant (ANOVA, $F_{2,12}=2.52, \mathrm{p}=0.12$ ). Oxygen availability was lowest in the hypoxia treatment $(\bar{x}=$ $63.96 \%$ air saturation, $\mathrm{SD}=9.2, \mathrm{n}=6$ ), intermediate in the normoxia treatment $(\bar{x}=96.56 \%$ air saturation; $\mathrm{SD}=1.52)$, and highest in the hyperoxia treatment $(\bar{x}=$ $160.49 \%$ air saturation; SD $=19.4$ ). Intracapsular oxygen availability was also compared among oxygen treaments and between early and late development using a 2-way ANOVA (fixed factors); data were square-root transformed to meet the assumptions of the ANOVA model. A 2-way ANOVA was also used to compare the gradient between extra- and intracapsular oxygen availability. In this case, no transformation was necessary. A posteriori Tukey tests (HSD) were conducted to determine differences among levels (Sokal \& Rohlf 1995).

At the end of incubation and after intracapsular oxygen availability was measured, some of the experimental capsules $(n=37)$ were examined under the microscope and the number of developing embryos was counted. In spite of the lack of significant differences in capsule size among oxygen partial pressure treatments, the number of embryos per capsule was standardized per mm of capsule, to compare them with other capsules (capsules collected in the field; see earlier subsection 'analysis of capsules'). The mean number of embryos that developed per mm capsule at the end of the experiment was compared among experimental treatments using a 1-way ANOVA (Model I; length was used based on the relationships presented in Fig. 1). A similar analysis (no transformation was necessary in this case) was conducted including counts from natural and experimental embryos. Data were not transformed because the assumptions of the ANOVA model were met. An a posteriori Tukey's test (HSD) was used to determine differences among treatments (Sokal \& Rohlf 1995).

\section{RESULTS}

The total number of eggs per capsule varied between 390 and 1175, and increased linearly with increasing capsule length (no. of eggs $=[164.9 \cdot \mathrm{CL}]-$ 819.1; $r^{2}=0.78 ; F_{1,35}=123.1, p<0.0001 ;$ Fig. 1a). The number of embryos per capsule varied between 33 and 116 embryos and also increased linearly with capsule length (no. of embryos $=[6.2 \cdot \mathrm{CL}]+6.2 ; r^{2}=0.78 ; F_{1,91}=$ 351.9, p < 0.0001; Fig. 1b).

Mean egg size varied with developmental stage. Mean egg length in newly deposited capsules was $226.28 \mu \mathrm{m}$ and in juveniles $931.19 \mu \mathrm{m}$ (Fig. 2a), representing an increase in size of $311 \%$ during embryonic development. 

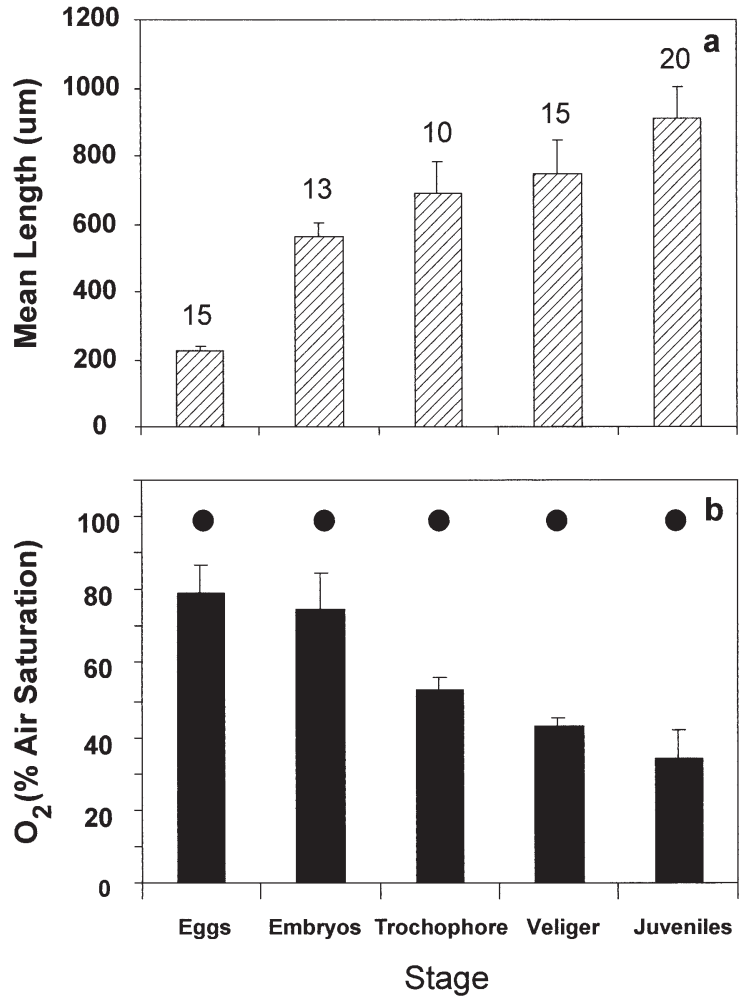

Fig. 2. Acanthina monodon. (a) Mean ( $\pm 1 \mathrm{SE}$ ) egg and embryo size throughout development; number of embryos measured from different capsules is indicated. (b) Mean ( \pm 1 SE) intracapsular oxygen availability (percent of air saturation) for the different developmental stages; (•) extracapsular oxygen availability, which was maintained atsaturation levels during the measurements

\section{Oxygen availability in capsules}

The mean intracapsular oxygen availability (\% air saturation) varied with embryo developmental stage (ANOVA, $F_{4,18}=23.16, \mathrm{p}<0.0001$; Fig. 2b). Intracapsular oxygen availability decreased as embryos developed; significant differences were found among early (egg to early trocophore), intermediate (trocophore-veliger) and late developmental stages ( $p<$ $0.05)$. No significant differences were found between egg and early trocophore, nor between trocophore and veliger $(\mathrm{p}>0.05)$. Extracapsular oxygen availability was $100 \%$ air saturation in all cases. As a consequence of the patterns of extra- and intracapsular oxygen among stages, the difference between extra- and intracapsular oxygen availability increased throughout development. This difference was smallest during early development (difference in \% air saturation in capsules containing eggs was $20.9 \%$, and for early trocophore $24.85 \%$ ), and largest for late developmental stages $(56.89 \%$ in capsules containing veliger, and $66.03 \%$ in capsules with juveniles).

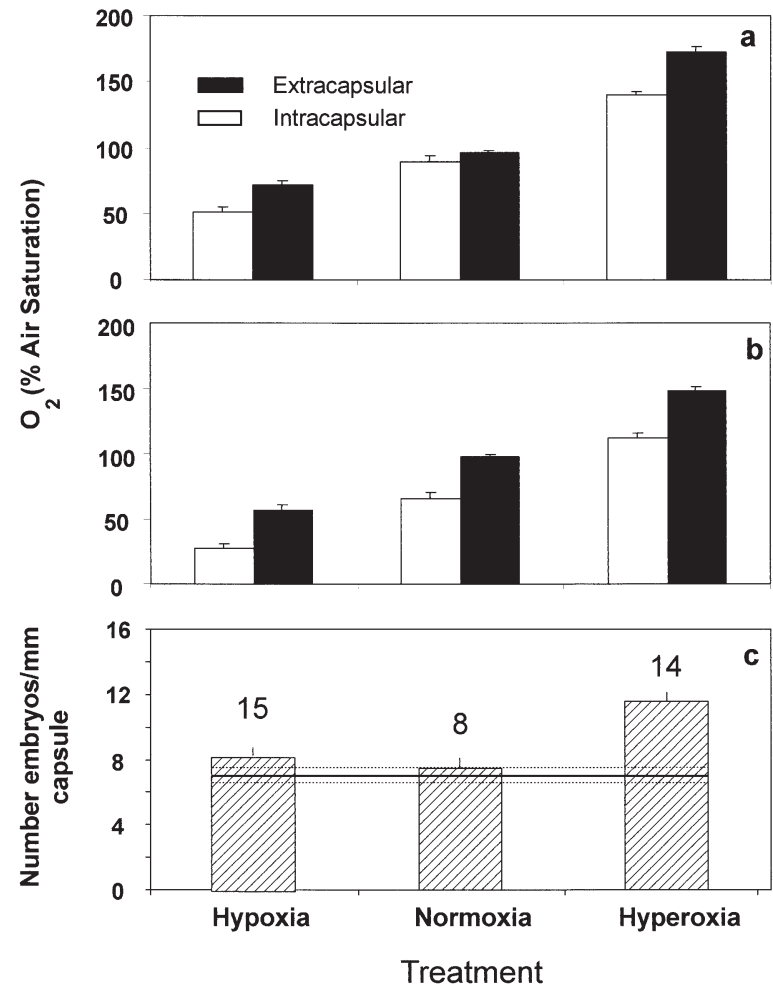

Fig. 3. Acanthina monodon. Mean intra- and extracapsular oxygen availability during early eggs (a) and late juveniles (b) development in experimental capsules maintained under different oxygen concentrations (hypoxia, normoxia and hyperoxia). (c) Mean ( $\pm 1 \mathrm{SE}$ ) number of embryos that developed under the 3 oxygen availability treatments standardized per millimeter of capsule. The continuous horizontal line is the mean number of embryos per millimeter of capsule in situ (broken lines: \pm 1 SD). Number of capsules analyzed in each case are shown (48 field-collected capsules were analyzed)

\section{Development of embryos in capsules under different experimental oxygen partial pressures}

Oxygen availability inside the capsules was significantly different among oxygen treatments (ANOVA, $\left.F_{2,12}=73.07, \mathrm{p}<0.0001\right)$ and between early and late stages of development (ANOVA, $F_{1,12}=16.61, \mathrm{p}=$ $0.0015)$. The interaction was not significant $\left(F_{2,12}=8.86\right.$, $\mathrm{p}=0.448$ ). Intracapsular oxygen availability was significantly lower in the hypoxia treatment $(\bar{x}=37.79 \%$ air saturation, $\mathrm{SD}=5.1$ ), intermediate under normoxia $(\bar{x}=70.75 \%$ air saturation, $\mathrm{SD}=5.1)$, and higher in the hyperoxia treatment $(\bar{x}=124.08 \%$ air saturation, $\mathrm{SD}=$ 5.1, p [always] < 0.05; Fig. 3a,b). Intracapsular oxygen availability was lower during late development $(\bar{x}=$ $65.56 \%$ air saturation, $\mathrm{SD}=4.16)$ than during early development $(\bar{x}=89.53 \%$ air saturation, $\mathrm{SD}=4.16, \mathrm{p}<$ 0.05 ; Fig. 3a,b). In all treatments there was a gradient 
between extra and intracapsular oxygen availability; the gradient was also significantly different among treatments (ANOVA, $F_{2,12}=7.88, \mathrm{p}=0.0065$ ) and between early and late development (ANOVA, $F_{1,12}=$ $21.74, \mathrm{p}=0.0005)$. The interaction term was not significant $\left(F_{2,12}=1.16, \mathrm{p}=0.35\right)$. Larger differences between intra- and extracapsular oxygen availability were found under hyperoxia $(\bar{x}=36.41 \%$ air saturation, $\mathrm{SD}=$ $1.98, p<0.05)$ than under hypoxia and normoxia $(p>$ 0.05 ; Fig. 3a,b). The difference between intra- and extracapsular oxygen availability was larger during late development $(\bar{x}=35.07 \%$ air saturation, $\mathrm{SD}=1.61)$ than during early stages of development $(\bar{x}=23.85 \%$ air saturation, $\mathrm{SD}=1.61, \mathrm{p}<0.05$; Fig. $3 \mathrm{a}, \mathrm{b}$ ).

The mean number of eggs (sum of nurse eggs and embryos) per unit capsule size (mm) was not significantly different among oxygen treatments $\left(F_{2,34}=1.59\right.$, $\mathrm{p}<0.217$ ), but the mean number of embryos that developed per unit of capsule size did vary among treatments (ANOVA, $F_{2,5}=47.17, \mathrm{p}<0.0006$ ). More embryos developed under hyperoxia than under the other 2 treatments $(\mathrm{p}<0.05 ;$ Fig. $3 \mathrm{c})$. No difference was detected between hypoxia and normoxia ( $p>0.05)$. The number of embryos that developed under normoxia and hypoxia per unit capsule size was similar to the number that developed in situ, and smaller than in the hyperoxia treatment (ANOVA, $F_{3,81}=22.83, \mathrm{p}<$ 0.0001; Fig. 3c).

\section{DISCUSSION}

The findings and implications of this study in relation to the effects of oxygen availability on early development can be divided into 3 categories: (1) new evidence of low oxygen availability in embryo aggregations in general (Booth 1995, Strathmann \& Strathmann 1995, Cohen \& Strathmann 1996, Lee \& Strathmann 1998, Fernández et al. 2000), and in encapsulated embryos, in particular (Cancino et al. 2000); (2) first evidence that the ratio between nurse eggs and embryos can be affected by oxygen availability, possibly through competition for oxygen among siblings; and (3) importance of incorporating oxygen availability during early development as a key factor for identifying trade-offs in life-history traits of marine invertebrates.

The effect of oxygen availability in egg aggregations of marine invertebrates during early development has been shown for several taxa (polychaetes, gastropods, crustaceans) and for different types of egg masses (gelatinous masses of different shapes, compact but non-gelatinous masses; see Booth 1995, Strathmann \& Strathmann 1995, Cohen \& Strathmann 1996, Lee \& Strathmann 1998, Fernández et al. 2000). Here we have shown that encapsulated embryos also experience low oxygen levels during development. Intracapsular oxygen availability tends to decrease throughout development in encapsulated eggs of gastropods (Perron \& Corpuz 1982, Cancino et al. 2000), as in other groups of marine invertebrates (Booth 1995, Cohen \& Strathmann 1996), presumably because of higher oxygen consumption of the embryos during late stages of development (Pechenik 1980, Gerdes 1983, Sprung 1984, Chaparro \& Paschke 1990). This supports previous findings indicating that, unless oxygen is actively provided and provision increases with development (Fernández et al. 2000, Baeza \& Fernández 2002), low oxygen concentrations in egg aggregations may occur during the late stages.

It is known that low oxygen availability affects (1) embryo oxygen consumption in marine invertebrate species, including gastropods (Booth 1995, Naylor et al. 1997, Fernández et al. 2000), and (2) developmental rate, producing an asynchrony in development between inner and outer embryos in gelatinous egg masses of gastropods and polychaetes (Chaffee \& Strathmann 1984, Strathmann \& Strathmann 1995, Cohen \& Strathmann 1996). Intracapsular oxgyen availability in Acanthina monodon may be low enough to affect oxygen consumption of the embryos and their development rate. In fact, the larger differences between extra- and intracapsular oxygen availability under hyperoxia than under hypoxia or normoxia may be related to a higher rate of oxygen consumption of the embryos at the latter 2 levels of oxygen partial pressure. This finding indirectly supports the idea that (1) at low oxygen partial pressure oxygen consumption decreases, and (2) oxygen is a limiting factor.

Based on the evidence presented above, we suggest that oxygen availability may limit embryo development in Acanthina monodon, affecting the number of embryos that develop per capsule. This implies that embryos may compete for a limiting resource such as oxygen, and as a result of this competition development of some eggs ceases. Lower oxygen availability and a lower number of embryos were found in protozoan-fouled capsules of Chorus giganteus compared to clean capsules (Cancino et al. 2000). We do not know if eggs cease development because they are inhibited by embryos with higher development rates, or if they arrest development due to low oxygen levels. Arrestment in embryo development has been shown for other marine invertebrates (Chaffee \& Strathmann 1984, Strathmann \& Strathmann 1995, Cohen \& Strathmann 1996), so it is a plausible hypothesis. Products of metabolism accumulating in egg aggregations do not seem to affect embryonic development as does oxygen limitation (Strathmann \& Strathmann 1995). In any case, inhibition or arrestment of development seems to 
be mediated by oxygen availability, since the ratio between nurse eggs and embryos can be altered by oxygen availability in encapsulated embryos (see also Cancino et al. 2000, who reported similar results). It is interesting that the number of embryos that developed under hypoxia and normoxia (and in situ) were similar, suggesting that development is not greatly affected between 50 and $70 \%$ air saturation (intracapsular; at least at $18^{\circ} \mathrm{C}$ ). Since at high temperatures the ratio of oxygen supply to demand decreases, a stronger effect among treatments would be expected at higher temperatures (Woods 1999), and probably differences between hypoxia and normoxia would appear.

We believe that oxygen availability alters the ratio between nurse eggs and embryos. This implies that females do not assign a fixed number of embryos per capsule. A parsimonious explanation could be that females deposit eggs that have the full potential to develop as embryos, and that the actual number that will attain full development is the result of competition for oxygen among siblings. This has already been suggested in the literature (Lee \& Strathmann 1998), and we believe that our results support this (see also the results of Cancino et al. 2000 for Chorus giganteus). Under this assumption, the number of embryos that develop would depend on the environmental conditions that the embryos experience during development. Thus, in cold waters, where metabolic rates decrease, oxygen consumption is low, and oxygen solubility increases, oxygen competition may decrease and more embryos may therefore develop. In fact, Cancino (pers. comm.) showed that the number of embryos that develop per capsule of $C$. giganteus increases as temperature decreases. This implies that conditions for the development of egg aggregations may be favorable at high latitudes (Thorson 1950). In summary, we suggest that the number of embryos that develop is not the maximum that a female can produce, and is probably not the optimum for the embryos either, but lies somewhere inbetween. This scenario is similar to the well-known parent-offspring conflict of terrestrial animals, although clutch size is determined before hatching and by a different factor, oxygen availability. Parent-offspring conflict over clutch size exists in nature, is more intense in cases of multiple paternity and small clutches, and should be favored when the cost of egg production is low and environmental changes unpredictable (Stearns 1992). We are not aware of single or multiple paternity in Acanthina monodon, but the cost of per-unit egg production is relatively low among marine invertebrates, and the environmental variables that could affect embryo development (e.g. oxygen availability, temperature) may vary greatly along the distributional range of the species, and among years for the same locality.
These results support the importance of incorporating oxygen availability during early development as a key factor for identifying trade-offs in the life histories of marine invertebrates. We think there is sufficient evidence that oxygen availability poses a constraint to brooding among different taxa of marine invertebrates. This constraint has an effect on total parental investment in reproduction (Fernández et al. 2000), on parental investment per offspring (Lee \& Strathmann 1998) and on clutch size (this study). The effect on clutch size may be the result of a compromise between the capacity of adults to invest in eggs, given the necessary additional investment in oxygen provision to the brood, and competition among siblings for a limiting resource (oxygen) that reduces initial clutch size (Lee \& Strathmann 1998). The interaction among siblings may range from negative effects on development rate (e.g. inner embryos in gelatinous masses, Lee \& Strathmann 1998) to changes in the ratio between nurse eggs and embryos (as in Acanthina monodon: this study). Thus, oxygen availability during early development could be one of the critical factors that causes deviations from the clutch size which optimizes individual fitness, at least in brooding species. The evaluation of the effect of oxygen availability during early development in determining the lifehistory traits of marine invertebrates (Strathmann \& Strathmann 1982) is also of interest when considering the differences between marine and terrestrial animals, and how these different constraints may contribute to the life-history theory. Among the most noticeable deviations from life-history assumptions are: (1) parental investment per offspring in marine invertebrates that suffer oxygen limitation is not independent of clutch size (Lee \& Strathmann 1998); (2) parental investment per offspring is influenced by total investment in a clutch (investment in jelly that helps oxygen diffusion: Lee \& Strathmann 1998); (3) competition among siblings occurs before hatching (Lee \& Strathmann 1998 and this study). Oxygen limitation during early development is common in most taxa of marine invertebrates, rather than being lineage-related (Chaffee \& Strathmann 1984, Strathmann \& Chaffee 1984, Booth 1995, Strathmann \& Strathmann 1995, Cohen \& Strathmann 1996, Cancino et al. 2000, Fernández et al. 2000).

Acknowledgements. We are grateful to many colleagues who helped us in different stages of this work: I. Albornoz, A. Baeza, F. Bozinovic, J. Cancino, F. Labra, P. Manriquez, P. Neill, J. M. Pulgar, B. Quinchalef, and R. Soto. We also thank 3 anonymous reviewers for their comments. M.A.L. was supported by a CONICYT Doctoral Fellowship. This study was supported by the FONDAP \#3 (Crustaceans) and the Volkswagen Foundation, the Humboldt Foundation, and FONDAP-FONDECYT (Grant 1501-0001). 


\section{LITERATURE CITED}

Baeza A, Fernández M (2002) Active brood care in Cancer setosus (Crustacea: Decapoda): the relationship between female behaviour, embryo oxygen consumption, and the cost of brooding. Funct Ecol 16:241-251

Booth D (1995) Oxygen availability and embryonic development in sand snail egg masses. J Exp Biol 198:241-247

Cancino JM, Gallardo CS, Torres F, Leiva G, Navarro JM (2000) Effects of sessile Protozoa in intracapsular oxygen tension and embryonic shell calcification in the muricid Chorus giganteus. Mar Ecol Prog Ser 200:141-148

Chaffee C, Strathmann RR (1984) Constraints on egg masses. I. Retarded development within thick egg masses. J Exp Mar Biol Ecol 84:73-83

Chaparro OR, Paschke KA (1990) Nurse egg feeding and energy balance in embryos of Crepidula dilatata (Gastropoda: Calyptraeidae) during intracapsular development. Mar Ecol Prog Ser 65:183-191

Clutton-Brock TH (1991) The evolution of parental care. Princeton University Press, Princeton

Cohen CS, Strathmann RR (1996) Embryos at the edge of tolerance: effects of environment and structure of egg masses on supply of oxygen to embryos. Biol Bull 190: 8-15

Crisp DJ (1959) The rate of development of Balanus balanoides embryos in vitro. J Anim Ecol 28:119-132

Fernández M, Bock C, Pörtner HO (2000) The cost of being a caring mother: the ignored factor in the reproduction of marine invertebrates. Ecol Lett 3:487-494

Gallardo CS (1979) Developmental pattern and adaptations for reproduction in Nucella crassilabrum and other muricacean gastropods. Biol Bull 157:453-463

Gallardo CS, Garrido O (1987) Nutritive egg formation in the marine snails Crepidula dilatata and Nucella crassilabrum. Int J Invertebr Reprod Dev 11:239-254

Gerdes D (1983) The Pacific oyster Crassostrea gigas. Part II. Oxygen consumption of larvae and adults. Aquaculture 31:221-231

Kohn AJ, Perron FE (1994) Life History and biogeography: pattern in Conus. Clarendon Press, Oxford

Lack D (1968) Ecological adaptations for breeding in birds. Methuen \& Company, London

Lee CE, Strathmann RR (1998) Scaling of gelatinous clutches: effects of sibling competition for oxygen on clutch size and parental investment per offspring. Am Nat 151:293-300

Naylor JK, Taylor EW, Bennett DB (1997) The oxygen uptake of ovigerous edible crabs (Cancer pagurus) and their eggs. Mar Freshw Behav Physiol 30:29-44

Editorial responsibility: Otto Kinne (Editor), Oldendorf/Luhe, Germany
Pechenik JA (1980) Growth and energy balance during the larval lives of three prosobranch gastropods. J Exp Mar Biol Ecol 44:1-28

Pechenik JA (1986) The encapsulation of eggs and embryos by molluscs: an overview. Am Malacol Bull 4:165-172

Perron FE (1981) Egg size distribution among closely related marine invertebrate species: are they bimodal or unimodal? Am Nat 118:749-755

Perron FE (1986) Life history consequences of differences in developmental modes among gastropods in the genus Conus. Bull Mar Sci 39:485-497

Perron FE, Corpuz GC (1982) Costs of parental care in the gastropod Conus pennaceus: age specific changes and physical constraints. Oecologia 55:319-324

Roff D (1992) The evolution of life histories. Chapman \& Hall, New York

Sokal RR, Rohlf FJ (1995) Biometry. The principles and practice of statistics in biological research, 3rd edn. WH Freeman \& Company, New York

Soto R (2001) Decisiones de forrajeo del gastrópodo murícido Nucella crassilabrum: rol de los componentes asociados a las restricciones fisiológicas, experiencia digestiva y al riesgo de la mortalidad. $\mathrm{PhD}$ thesis, Pontificia Universidad Católica de Chile

Spight T (1976) Hatching size and the distribution of nurse eggs among prosobranch embryos. Biol Bull 150:491-499

Sprung M (1984) Physiological energetics of mussel larvae (Mytilus edulis). III. Respiration. Mar Ecol Prog Ser 18:171-178

Stearns SC (1992) The evolution of life histories. Oxford University Press, Oxford

Strathmann RR, Chaffee C (1984) Constraints on eggs masses. II. Effects of spacing size and number of eggs on ventilation of masses of embryos in jelly, adherent group, or thinwalled capsules. J Exp Mar Biol Ecol 84:85-93

Strathmann RR, Strathmann MF (1982) The relationship between adult size and brooding in marine invertebrates. Am Nat 119:91-101

Strathmann RR, Strathmann MF (1995) Oxygen supply and limits on aggregation of embryos. J Mar Biol Assoc UK 75: $413-428$

Thorson G (1950) Reproductive and larval ecology of marine bottom invertebrates. Biol Rev 25:1-45

Valentine J, Jablonski D (1983) Larval adaptations and patterns of brachiopods diversity in time and space. Evolution 37:1052-1061

West DL (1981) Reproductive biology of Clolus stimpsoni. IV. Oogenesis. The Veliger 24:28-38

Woods H (1999) Egg-mass size and cell size: effects of temperature on oxygen distribution. Am Zool 39:244-252

Submitted: December 10, 2001; Accepted: April 25, 2002

Proofs received from author(s): July 30, 2002 